\title{
Common Risk Factors in Stock Returns in the MENA Region
}

\author{
Rasha Abadi* and Florinda Silva
}

\begin{abstract}
Manuscript type: Research paper

Research aims: This paper examines risk factors comprising size, value, profitability, investment, momentum and illiquidity to see if they are relevant for the stock markets in the Middle East and North Africa (MENA) region.

Design/Methodology/Approach: Stock market data, from January 2007 to December 2015, are used to construct the risk factors for the stock market in the MENA region. The single factor models and the multifactor models are used to explain the constructed portfolios' excess returns.

Research findings: Findings show that the risk factors of size, value and profitability are the most important to be applied in asset pricing models within the MENA region. In addition, most of the models analysed in this study are unable to perfectly capture the average excess returns of the datasets, with the seven-factor model performing better than the other competing models.

Theoretical contribution/Originality: This paper is possibly one of the first to construct and apply the above-mentioned risk factors in the MENA markets. It further proposes using two additional risk factors, such as momentum and illiquidity, within the Fama and
\end{abstract}

* Corresponding author: Rasha Abadi is an Associate Professor of Finance at the NIPE School of Economics and Management, University of Minho, Braga, Portugal and Department of Finance, Arab American University, Palestine. Email: rasha.abbadi@aaup.edu Florinda Silva is an Associate Professor of Finance at the NIPE - School of Economics and Management, University of Minho, 4710-057, Braga, Portugal. Email: fsilva@eeg.uminho.pt

Acknowledgement: This research was supported by the funding from COMPETE (reference no. POCI-01-0145-FEDER006683), FCT/MEC's (Fundaçãopara a Ciência e a Tecnologia, I.P.) and ERDF through the Operational Programme of Competitiveness and Internationalization COMPETE2020 under the PT2020 Partnership Agreement.

https://doi.org/10.22452/ajba.vol12no2.2 
French's three-factor and five-factor models so as to examine the stock markets of the MENA region. Other researchers before have not made this proposition.

Practitioner/Policy implication: The findings raise the awareness that additional and important factors must be considered by investors in the emerging financial markets when they want to diversify the risks so as to achieve higher excess returns.

Research limitation/Implications: This study also has some drawbacks in that the dataset period is short while the analysis comprises different markets with different levels of development, thereby affecting some degree of generalisability.

Keywords: CAPM, Factor Models, Illiquidity Factor, MENA Market JEL Classification: G12

\section{Introduction}

Early empirical studies have revealed that the capital asset pricing model (CAPM) has not performed efficiently in the stock market (Fama \& French, 1992; Basu, 1983; Banz, 1981). Many academics and practitioners claim that the simple CAPM cannot fully capture the cross-sectional components of various stock returns. Past studies have shown that using a combination of risk factors is better for explaining stock excess returns than using a single factor model. This insight has led to the development of multifactor models which use more than one priced risk factor in a classic model, such as the CAPM by combining it with other market factors. These market factors may include size and value (Fama \& French, 1993), lagged momentum (Jegadeesh \& Titman, 1993; Carhart, 1997), profitability and investment (Fama \& French, 2015), and illiquidity (Amihud, 2002).

The first three-factor model proposed by Fama and French (1993) had been successful in capturing stock excess returns, but Brailsford, Gaunt and O'Brien (2012) stated that it does not explain the non-linear relationship between size and returns. Nonetheless, Fama and French's three-factor model outperformed the CAPM in explaining the average stock returns. In that regard, Fama and French's three-factor model was not considered a complete model, hence more factors were added. Carhart (1997) extended the three-factor model by adding momentum while Amihud (2002) added the illiquidity factor, so as to explain stock returns. Fama and French (2015) then added the profitability factor which was first proposed by Novy-Marx (2013), and the investment factor, which was first introduced by Aharoni, Grundy and Zeng (2013), 
in the effort to combine all these factors into one model, the new fivefactor model. This new model was noted by Fama and French (2015) to perform well in explaining the average excess returns. However, it was unable to fully capture all the excess returns. Following this, Hou, Xue and Zhang (2015) proposed the q-factor model (a four-factor model) which combined the profitability, investment, market and size factors together. Their findings revealed that the q-factor model outperformed Fama and French's (1993) three-factor model, and Carhart's (1997) fourfactor model, in explaining the market anomalies. Several studies have highlighted the importance of all these risk factors mentioned above, but this was exclusively for the US and other developed markets. Emerging markets have not been studied at the same level in detail despite the fact that emerging stock markets have an important role to play within the world portfolio. The importance of such emerging economies, and stock markets are constantly increasing (Hanauer \& Linhart, 2015), hence such markets should not exist in obscurity.

The current study aims to address part of that issue by giving focus to the Middle East and North Africa (MENA) markets as emerging markets. Comparatively, the MENA markets are less developed than the Asian or Latin American markets. Additionally, they are also relatively small, illiquid, less transparent and mainly dominated by the banking system (Lagoarde-Segot \& Lucey, 2008). The MENA markets are also characterised by attributes such as economic, currency, liquidity, institutional and political risks. They are also seen to be less efficient markets with a high proportion of small companies that play a fundamental role in asset allocations. Despite all these characteristics of the MENA region, it seems pertinent to ask if those risk factors found in developed and other developing markets may also affect the equity markets of the MENA region. Thus far, there are no sources available to update the risk factors of the stock markets in the MENA region. For the purpose of this study, we computed our own risk factors so as to examine the risk factors which are most frequently used to explain the stock excess returns in the MENA region. This study is motivated by previous discussions on using alternative asset pricing models to explain stock excess returns, and on using different datasets to validate these factor models. In this study, we analyse the effects of the size, value, profitability, investment, momentum and illiquidity factor on the stock markets of the MENA region.

It is anticipated that this study would contribute to knowledge on risk factors of the equity markets in the following ways. First, to the best of our knowledge, this paper is one of the first few to analyse Fama and 
French's (2015) five-factor model in the MENA markets. Second, this study proposes additional risk factors such as momentum and illiquidity to be added to Fama and French's (1993) three-factor model and Fama and French's (2015) five-factor model in the context of the MENA region. Third, the construction of these factors serves as the first step in creating a database for the MENA region. This database is similar to that of the Fama and French's database. This accessibility will allow future researchers to study the MENA region with more in-depth in other areas of interest, such as asset pricing, market efficiency, or even portfolio performance evaluation. Fourth, this study contributes to current literature by indicating that more than one test is used to compare the performance robustness of all the models analysed.

The remainder of this paper is structured in the following manner. Section 2 illuminates the literature review relevant to the different risk factors and asset pricing models. Section 3 describes the factors and the portfolios' construction methods. Section 4 presents the datasets and variables' definitions. Section 5 presents the findings and discussion and Section 6 concludes.

\section{Literature Review}

Risk factors affecting stock market returns have been a fundamental debate of modern finance, and the model most commonly used in relation to stock returns calculations is the CAPM model (Treynor, 1962; Sharpe, 1964; Lintner, 1965; Mossin, 1966). According to this model, investors are rewarded for the systematic risks which cannot be diversified. Among the many risk factors involved, market factors are the most important, as noted by most early CAPM-related literature. Researchers all over the world are hoping to identify other risk factors which may be able to explain the returns of various securities. Nonetheless, risk factors cannot be easily specified because it is difficult to determine the number and the nature of these factors. Ross (1976) developed the arbitrage pricing theory (APT) by arguing that expected returns can be determined based on different macroeconomic factors, but the APT cannot clearly identify what these factors are since they are likely to vary over time, and across markets.

Following this, other models were developed and Rosenberg and Marathe (1976) were among the first to develop the multifactor model, after which Fama and French used Merton's (1973) intertemporal capital asset pricing model (ICAPM) to convert it into a multifactor model. Fama and French $(1993,2015,2016)$ had proposed several multi- 
factor models which include various other factors such as market, size, value, investment and profitability. The various models proposed by Fama and French $(1993,2015,2016)$ had also been extended before, for instance, by Carhart (1997) who added the momentum factor. All of these models have today become the standard models mostly discussed by finance literature.

Fama and French's (1993) innovative work showed that the US stock returns can be explained by factors (size and value) besides its market risk premium. It was documented that the market risk premium, size and value factors, played an important role in explaining the expected returns. Fama and French's (1993) three-factor model has been regularly used in many equity markets around the world. However, the results gathered vary from one study to another. As an illustration, Griffin (2002) applied Fama and French's three-factor model to study the market of different countries. It was found that the model performed well, depending on the respective country rather than on a global basis.

Barry, Goldreyer, Lockwood, and Rodriguez (2002) also used Fama and French's three-factor model to examine 35 emerging markets in the world. They found that the value factor was relevant in all those markets. In contrast, the size factor effect would depend on the method used for calculating the size as well as the inclusion of extreme size values. In a similar study investigating the markets of 32 countries, Van der Hart, Slagter and Van Dijk (2003) found that both the size and value factors were relevant risk factors. In another study, Liu, Stambaugh and Yuan (2018) excluded the smallest 30 per cent of firms, which were valued significantly, to construct the value and size factors for the market of China. They found that the model using this construction outperformed the model that was constructed based on Fama and French's (1993) model. Liu et al. (2018) argued that their model was able to explain the profitability and volatility of the Chinese anomalies. More recently, Hu, Chen, Shao and Wang (2019) investigated the size and value factors in the cross-sectional returns of the Chinese stock market. They found that stock returns were strongly related only to firm size. They explained that these results contradicted some of the previous literature due to the short sample period used.

The empirical asset pricing researchers propose new factor models to improve the three-factor model performance. Carhart (1997) extended the three-factor model with a fourth factor: momentum. By addressing one of the biggest anomalies, the explanatory power of the Fama and French three-factor model was improved. While Carhart's (1997) model has been extensively tested in various markets, Jegadeesh and 
Titman (1993), and Lo and MacKinlay (1990) were among the first few to document the basic idea of the momentum effect. They found that investors can earn profits of approximately one per cent per month if they hold stocks with high returns over the preceding months, and sell stocks with low returns within the same time period. Cakici, Fabozzi and Tan (2013) examined the value and momentum effects of 18 emerging stock markets. They confirmed the existence of the value and momentum effects in all the 18 emerging markets, but not for Eastern Europe (no momentum). Hanauer and Linhart (2015) also used the Carhart model to examine four emerging market regions: Latin America, EMEA (Europe, the Middle East and Africa), BRIC (Brazil, Russia, India, and China) and Asia. They detected a strong evidence noting the effect of the value factor, but they had weak evidence noting the effect of the momentum factor in those regions. Blackburn and Cakici (2017) used the CAPM and the Carhart four-factor model to examine the stock returns market in Europe, Africa, the Middle East and Asia. They discovered that value and momentum were significant risk factors for those four markets, including small and large stocks. They also found that the Carhart four-factor model outperformed the CAPM.

Motivated by the dividend discount valuation model, and based on anomalies not considered by the three-factor and four-factor models, Fama and French (2015) further improved on the three-factor model by adding two additional factors - profitability and investment. These two factors exemplified what is universally known as quality factors. Fama and French (2015) found that the new model performed better than their three-factor model. The five-factor model was then tested on international regional data by Fama and French (2017). They found that the current model revealed significant differences for the different countries such as North America, Europe, Asia-Pacific and Japan. Still focussing on the CAPM model, Hou, Xue and Zhang (2015) proposed the four-factor q model which contained the market and size factor combined with the profitability and investment factor. They concluded that the q-factor model had outperformed the three-factor model and Carhart's (1997) four-factor model in explaining the market anomalies. More recently, Hou, Mo, Xue and Zhang (2019) compared alternative asset pricing models by using Fama and French's (2015) five-factor model, and Hou et al.'s (2015) q-factor model. It was observed that the latter, the q-factor model, outperformed the five-factor model.

More recent studies (Barillas \& Shanken, 2018; Fama \& French, 2018) attempted to develop a six-factor model by including an additional 
factor, momentum, into Fama and French's (2015) five-factor model. It was deduced by Barillas and Shanken (2018) that models which included the momentum, value and profitability factors, and which were updated on a monthly basis, dominated both Fama and French's (2015) fivefactor model, and Hou et al.'s (2015) q-factor model. Based on this, Fama and French (2018) concluded that the six-factor model which combined small and big stocks to measure value, profitability and investment were similar to their model that was without the momentum factor.

Besides the momentum factor, other factors such as illiquidity also affect stock returns. The pioneering studies of Amihud and Mendelson (1986), and Brennan and Subrahmanyam (1996), noticed that illiquidity affected asset pricing. Since illiquidity was found to be a fundamental factor that captured stock returns, numerous illiquidity measures had been used. The illiquidity ratio was noted to be a frequently used measure (Amihud, 2002), but more recently, there have been studies analysing illiquidity as a risk factor. The basis for most studies was derived from the CAPM, Fama and French's three-factor, and fivefactor models. Most of the studies looking at illiquidity effects have been conducted in developed markets. For instance, Dey (2005) used the turnover ratio as a measure of illiquidity to assess the determinants of returns variation for 49 global markets. The results showed a positive and significant relationship between returns and illiquidity, but only for emerging markets. In contrast, Rouwenhorst (1999) found that average stock returns in emerging markets were not affected by stock turnover as a measure of illiquidity. Hearn (2009), and Hearn and Piesse (2010) had both used illiquidity, market, value and size to examine the small and liquid market of East Africa as well as the larger cross section of the other African markets. Both studies noted that illiquidity, market, value and size were relevant to those markets.

Based on the outcomes mentioned above, we thus conclude that the findings of previous studies for emerging markets had been inconsistent. In addition, there are limited evidence to show the performance of these asset pricing models in the MENA region. Although Fama and French's three-factor model had been applied in a few studies including some of the MENA countries, to the best of our knowledge, no study had attempted to analyse either the five-factor model or the six-factormomentum model in the MENA region. Moreover, no study had examined the six-factor-illiquidity and the seven-factor models in any equity market. The limited studies in this aspect may be explained by the lack of a comprehensive, high-quality accounting database. However, 
with the development and increasing importance of finance and stock returns, it seems unfair not to include the MENA stock markets as globalisation transforms the landscape. Thus, the current study is conducted to contribute to existing literature and to provide empirical evidence gathered from the analysis of new and different datasets from the MENA region. The fact that the MENA region is composed of equity markets characterised by different levels of development, political and economic instability makes the region an interesting focus. Nonetheless, the outcome derived from this study may or may not show the applicability of these factors within the MENA markets.

\section{Methods}

This study uses the time-series estimation method to evaluate alternative asset pricing models. In the context of this study which embraces the MENA markets, we analysed the CAPM, Fama and French's (1993) three-factor model, Carhart's (1997) four-factor model, Fama and French's (2015) five-factor model, the four-factor-illiquidity model, the six-factor-illiquidity model, the six-factor-momentum model, and also the seven-factor model. In total, we analysed eight models. Based on this, the first step of our study is to examine the ability of these factors in explaining portfolio excess returns while the second step is to determine the best combination of these factors to be used for explaining the average excess returns in the MENA region.

\subsection{Factors Construction}

To construct the factors, we used the Fama and French $(1993,2015)$ method, and the six-form portfolios. These portfolios were constructed in December for each year. ${ }^{1}$ We assume that these hypothetical portfolios are held without trading for the next twelve months so as to minimise transaction costs that are associated with portfolio management. Since we do not have access to the MENA indices' constituents, we are unable to use the median of an existing index. To remedy this issue, we adopted the median of the market values of the companies listed in the datasets. In this regard, the size breakpoints were used to distinguish the large stocks from the small stocks. Likewise, the breakpoints of the book-to-

\footnotetext{
${ }^{1}$ To avoid the look-ahead bias, we lagged our data one year to be sure that at the end of each December, we have all the required variables.
} 
market (B/M) ratio, profitability (OP), and investment (INV), lagged momentum (MOM), and illiquidity (ILLIQ) can divide the samples into different groups. The factors that were constructed from this method are called small minus big (SMB), high minus low (HML), conservative minus aggressive (CMA), robust minus weak (RMW), winner minus loser (WML), and illiquid minus liquid (ILML).

In December of every year, all stocks were sorted and grouped into two size portfolios. The first portfolio is the small (S) portfolio, which is composed of stocks with the lowest 50 per cent of the region's total market capitalisation (MC). The second portfolio is the big (B) portfolio, which is composed of stocks with the highest 50 per cent of the region's total MC. ${ }^{2}$ Independently, all stocks fulfilling the selection criteria were sorted based on their $\mathrm{B} / \mathrm{M}$ ratio. They were then grouped into three value portfolios. We determined the lowest 30 per cent (growth $(\mathrm{G})$ ), the middle 40 per cent (neutral $(\mathrm{N})$ ), and the top 30 per cent (value $(\mathrm{V})$ ) breakpoints for $\mathrm{B} / \mathrm{M}$. Based on the intersection of the size, and the $\mathrm{B} / \mathrm{M}$ quantiles, we constructed six portfolios: SG, SN, SV, BG, BN and BV. These portfolios were then held for the subsequent twelve months, and the value-weighted returns were then calculated for the period from December year $t$ to December year $t+1$. We repeated the same procedure at the end of the holding period. Each year, the six portfolios were then rebalanced based on the new values of the $\mathrm{MC}$, and the $\mathrm{B} / \mathrm{M}$ ratio. In the $2 \times 3$ sorts, the SMB and HML were calculated as follows:

$$
\begin{aligned}
& S M B=1 / 3 \times(S V+S N+S G)-1 / 3 \times(B V+B N+B G) \\
& H M L=1 / 2 \times(S V+B V)-1 / 2 \times(S G+B G)
\end{aligned}
$$

We constructed the OP factor in a similar way by determining the lowest 30 per cent (Weak (W)), the middle 40 per cent (Neutral (N)), and the top 30 per cent (Robust (R)) breakpoints for the OP variable. We then applied these breakpoints to the large and small stocks. From the intersection of the relevant size, and OP quantiles, we constructed six portfolios: $\mathrm{SR}, \mathrm{SNOP}, \mathrm{SW}, \mathrm{BR}, \mathrm{BNOP}$, and $\mathrm{BW}$. We also determined the lowest 30 per cent (Conservative $(C)$ ), the middle 40 per cent (Neutral (N)), and the top 30 per cent (Aggressive (A)) breakpoints for the INV variable by applying these breakpoints to the large, and

\footnotetext{
${ }^{2}$ We also applied different breakpoints for our sample (e.g., top 30 per cent (10 per cent) and bottom 70 per cent $(90$ per cent)), to see if there is any effect of the breakpoint on the results. We obtain similar results for the different breakpoints.
} 
small stocks. From the intersection of the relevant size, and INV quantiles, we constructed six portfolios: SC, SNINV, SA, BC, BNINV, and BA. All these OP, and INV portfolios were then held for the next twelve months, and the value-weighted returns were calculated on the portfolios for the period from December year $t$ to December year $t+1$. In the $2 \times 3$ size-OP sorts, and $2 \times 3$ size-INV sorts, the RMW and CMA were calculated as follows:

$$
\begin{aligned}
& R M W=1 / 2 \times(S R+B R)-1 / 2 \times(S W+B W) \\
& C M A=1 / 2 \times(S C+B C)-1 / 2 \times(S A+B A)
\end{aligned}
$$

In the $2 \times 3$ size- $\mathrm{B} / \mathrm{M}$ sorts, $2 \times 3$ size-OP sorts and $2 \times 3$ size-INV sorts, $\mathrm{SMB}$ is the average return on the nine small stock portfolios minus the average return on the nine large stock portfolios. The SMBB, SMBOP, SMBINV and SMB were calculated as follows:

$$
\begin{aligned}
& S M B_{B / M}=1 / 3 \times(S V+S N+S G)-1 / 3 \times(B V+B N+B G) \\
& S M B_{O P}=1 / 3 \times\left(S R+S N_{O P}+S W\right)-1 / 3 \times\left(B R+B N_{O P}+B W\right) \\
& S M B_{I N V}=1 / 3 \times\left(S C+S N_{I N V}+S A\right)-1 / 3 \times\left(B C+B N_{I N V}+B A\right) \\
& S M B=1 / 3 \times\left(S M B_{B / M}+S M B_{O P}+S M B_{I N V}\right)
\end{aligned}
$$

Based on size and MOM, we further constructed six portfolios. At the end of each month, all stocks are sorted, and grouped into two portfolio sizes. Independently, we sorted the MOM and determine the lowest 30 per cent (Losers (L)), the middle 40 per cent (Neutral $\left(\mathrm{N}_{\text {mom }}\right)$ ), and the top 30 per cent (Winners $(\mathrm{W})$ ). The intersection of the independent sorts on size and MOM produce six portfolios: $\mathrm{SL}, \mathrm{SN}_{\text {mom }}$ $\mathrm{SW}, \mathrm{BL}, \mathrm{BN}_{\mathrm{mom}}$ and $\mathrm{BW}$. The value-weighted monthly returns on portfolios were computed each month from December $t$ to December $t+1$. The WML was calculated as follows:

$$
W M L=1 / 2 \times(S W+B W)-1 / 2 \times(S L+B L)
$$

To construct the ILLIQ factor, a similar procedure was used. For both the small and large size portfolios, the stocks were sorted into three separated ILLIQ-ranked portfolios: the lowest 30 per cent (Liquid, (L)), the middle 40 per cent (Neutral, (NILLIQ)), and the highest 30 per cent (Illiquid, (IL)). This generates six size-ILLIQ portfolios: SIL, SNILLIQ, SL, BIL, BNILLIQ and BL. The low values of the ILLIQ measure indicate 
high liquidity, whereas the high values of the measure indicate high ILLIQ. The value-weighted monthly returns on the portfolios were computed each month from December $t$ to December $t+1$. The ILML was calculated as follows:

$$
I L M L=1 / 2 \times(S I L+B I L)-1 / 2 \times(S L+B L)
$$

\subsection{Portfolio Construction}

This sub-section describes the construction of the portfolios used as dependent variables. Based on the size, and the B/M equity ratio, we constructed 25 portfolios. These portfolios were formed in the same way as the six size-B/M portfolios described above. In December of each year, we allocated the MENA stocks to five portfolio sizes, based on the MC. We then independently chose five value portfolios based on the $\mathrm{B} / \mathrm{M}$. From the intersections of the size and the value portfolios, we constructed 25 portfolios. In the same way, we constructed 25 portfolios based on size and the OP variable, 25 portfolios based on size and the INV variable, and 25 portfolios based on size and the MOM variable. Then, we calculated the value-weighted monthly returns on the portfolios from December $t$ to December $t+1$.

To examine possible ILLIQ effects, we sorted the stocks into three portfolios based on ILLIQ. Independently, we sorted the stocks into three portfolios according to size. From the intersections of the size, and the ILLIQ portfolios, we constructed nine portfolios. The value-weighted monthly returns on the portfolios from December $t$ to December $t+1$ were calculated. In this set, we constructed only nine portfolios because the number of stocks that have information on the ILLIQ ratio is small.

\subsection{Model tests}

Using the excess returns on the portfolios, and the factor returns described above, we tested different asset pricing models for the MENA region. These tests were performed using the time-series regression approach represented by equations (11) to (18).

$$
\begin{aligned}
& \text { The CAPM } \\
& R_{P, t}-R_{f t}=a+\beta\left(R_{M, t}-R_{f t}\right)+\varepsilon_{t} \\
& \text { The three-factor model } \\
& R_{P, t}-R_{f t}=a+\beta\left(R_{M, t}-R_{f t}\right)+s(S M B)+h(H M L)+\varepsilon_{t}
\end{aligned}
$$


The four-ILLIQ model

$R_{P, t}-R_{f t}=a+\beta\left(R_{M, t}-R_{f t}\right)+s(S M B)+h(H M L)+i l(I L M L)+\varepsilon_{t}$

The four-MOM model

$R_{P, t}-R_{f t}=a+\beta\left(R_{M, t}-R_{f t}\right)+s(S M B)+h(H M L)+m(W M L)+\varepsilon_{t}$

The five-factor model

$R_{P, t}-R_{f t}=a+\beta\left(R_{M, t}-R_{f t}\right)+s(S M B)+h(H M L)+c(C M A)+r(R M W)+\varepsilon_{t}$

The six-ILLIQ model

$R_{P, t}-R_{f t}=\alpha+\beta\left(R_{M, t}-R_{f t}\right)+s(S M B)+h(H M L)+c(C M A)$

$+r(R M W)+i l(I L M L)+\varepsilon_{t}$

The six-MOM model

$R_{P, t}-R_{f t}=\alpha+\beta\left(R_{M, t}-R_{f t}\right)+s(S M B)+h(H M L)+c(C M A)$

$+r(R M W)+m(W M L)+\varepsilon_{t}$

The seven-factor model

$$
\begin{aligned}
& R_{P, t}-R_{f t}=\alpha+\beta\left(R_{M, t}-R_{f t}\right)+s(S M B)+h(H M L)+c(C M A)+r(R M W) \\
& +m(W M L)+i l(I L M L)+\varepsilon_{t}
\end{aligned}
$$

where, $R_{P, t}-R_{f t}$ is the continuously compounded return on the stock portfolio $p$ in excess of the risk-free rate, $R_{M, t}-R_{f t}$ is the continuously compounded return on a market benchmark in excess of the risk-free rate, $S M B$ is the average return difference between small and large portfolios, $H M L$ is the average return difference between value and growth portfolios, $R M W$ is the average return difference between robust and weak portfolios, CMA is the average return difference between conservative and aggressive portfolios, $W M L$ is the average return difference between winner and loser portfolios, and ILML is the average return difference between illiquid and liquid portfolios.

Five sets of the left-hand side (LHS) portfolios were used to evaluate each model. We used the Gibbons, Ross and Shanken (1989) test (GRS) to analyse whether the pricing errors of all the portfolios in each size set was jointly equal to zero. This enables us to evaluate and compare the various models accurately. We ran individual ordinary least squares (OLS) regressions to obtain the model parameter estimates. If the model capture all the variations in the returns, the intercept $\alpha$ in each model should be zero for all portfolios. In addition to the GRS, 
and the OLS estimates, we also reported on the Akaike information criteria (AIC) of all the models, and the adjusted $\mathrm{R}^{2}$ differences between the models. We calculated the average of the portfolios for the AIC values in order to determine the AIC in each LHS portfolio set for each model. To investigate whether all the models' performance would be significantly different, we applied the bootstrapping method to find the mean adjusted $\mathrm{R}^{2}$ for each model in each portfolio set, and also to test the difference between the adjusted $\mathrm{R}^{2}$ for each of the two models.

\section{Data and Variables Definition}

\subsection{Data}

Our datasets are composed of non-financial firms listed on all exchanges of 13 countries in the MENA region. These countries comprise Bahrain, Egypt, Israel, Jordan, Kuwait, Lebanon, Morocco, Palestine, Oman, Qatar, Saudi Arabia, Tunisia, and the United Arab Emirates. ${ }^{3}$ The required data were extracted from Thomson Reuters DataStream database. The period set for the datasets were from December 2004 until December 2015, but the first two years (2004 to 2006) were lost due to the construction of the INV and MOM factors. Consequently, the data samples compiled for the study were from the sample period of January 2007 to December 2015 (a total of eight years). The dataset period was selected due to the need to maintain the historical contents for as long as possible, and to have a coverage of markets that is as broad as possible. We note that there were extremely few or no financial market in the MENA region which carry any available data prior to 2005, hence we made it our choice to ensure that the data we collected would reflect those that would be readily available for all markets. Hence, we included all the non-financial companies ${ }^{4}$ that are listed in the MENA exchange markets. To standardise the data which were accumulated from the different countries in the MENA region with different currencies, we converted all the data into US dollars.

From the compilation of our dataset, we selected those stocks which carry information on the MC, and on the following accounting variables: annual revenues, cost of goods sold, interest expenses, selling, general

\footnotetext{
${ }^{3}$ We base on the United Nations' website to define the MENA countries. These 13 countries are the only MENA countries that are included on the DataStream and have data.

${ }^{4}$ Banks and insurance companies are excluded.
} 
and administrative expenses, book value of equity, INV tax credits, deferred taxes, preferred stocks, total assets, number of outstanding shares, daily total returns index, daily number of trading stocks and daily closing prices. We also used the monthly total returns index (RI) for our returns calculation. All these variables were used to construct the different factors. As mentioned earlier, we referred to the DataStream database for our data. In some cases, we also collected data from various companies' financial reports which are obtained from the companies' websites, and from corresponding equity markets' official websites. ${ }^{5}$ Thus, we used manually collected data to enlarge our samples in order to ensure that we had included all the listed non-financial companies. With regards to the risk-free rate, we used the US T-Bill once a month rate because all our data were in USD rate. We obtained the risk-free rate from the Kenneth French data library. To avoid a possible survivorship bias, delisted stocks were included until they disappeared. In the current study, we only included the equity-type securities while excluding the preferred shares from the database. Firms with negative book equity, and some outliers were also excluded. ${ }^{6}$

\subsection{Variables Definition}

To define the variables used, the following data were used for calculation purposes, and for the required variables of the portfolios, and the factors' construction:

- Book Value (BV) is the BV of equity plus balance sheet deferred taxes, and investment tax credits minus the BV of preferred stocks. We calculated this variable annually at the end of each fiscal year for each company.

- $\quad \mathrm{MC}$ is the closing stock price multiplied by the number of outstanding shares at the end of each year. It was used for computing the value-weighted returns, size, values and the $\mathrm{B} / \mathrm{M}$ ratio.

- $\quad$ The B/M ratio was used to construct the portfolios in December of year $t$, based on the values of the BV of equity for the year $t-1$, divided by the MC at the end of December of year $t-1$.

\footnotetext{
${ }^{5}$ The majority of the companies in the MENA region use the International Financial Reporting Standards (Mwaura and Nyaboga, 2011).

${ }^{6}$ Two firms with stock returns equal to or higher than 200 per cent were excluded since this value was very large compared to the other returns.
} 
- OP was used to construct the portfolios in December of year $t$, based on the operating incomes (measured as annual revenues minus cost of goods sold, selling, general, and administrative expenses), after interest expenses of year $t-1$, divided by BV of year $t-1$.

- INV was used to construct the portfolios in December of year $t$ based on the total assets at the end of year $t-1$, minus total assets at the end of year $t-2$, divided by total assets at the end of year $t-2$.

- ILLIQ, following Amihud's (2002) definition, was used to construct the portfolios in December of year $t$, based on the monthly ILLIQ ratio. The daily ILLIQ ratio was measured as the absolute value of daily stock returns divided by the daily trading volume (the daily stock price multiplied by the daily number of trading stocks). The monthly ILLIQ ratio was calculated as the average of the daily ILLIQ ratio for each stock in each month.

- MOM, following Jegadeesh and Titman (1993), was the common measure of the past 12 months' cumulative return on the stock, MOM2-12. This measure skips the most recent month's return in order to avoid the one-month's reversal in stock returns, hence the MOM was the stock's cumulative return for $t-12$ to $t-2$.

- Market returns $\left(R_{M, t}\right)$ was the market returns calculated as the equally weighted monthly returns of all shares, which have the available data plus the negative $\mathrm{B} / \mathrm{M}$ stocks which were excluded earlier when the factors and portfolios were constructed.

- We used the simple average to create a more diversified index with a bigger mid-cap base rather than concentrating on the largest companies. ${ }^{7}$

In general, most of the market indices have used the valueweighted average returns for the stocks that were included in the index. The problem, however, is that these market indices could be biased by the existence of large and liquid listed companies. Thus in this study, we used an equally weighted index that concentrated more on the

\footnotetext{
${ }^{7}$ The value-weighted index was also used; we notice that there is no huge difference in the results, but the equally weighted index gives higher $\mathrm{R}^{2}$.
} 
higher growth potential stocks which also comprised the small and midcap stocks. Indeed, most of the stocks in our samples were classified as small and mid-cap stocks. Therefore, we used the equally weighted market portfolio including all the stocks to limit the effect of the biggest companies on the overall portfolio performance.

\subsection{Summary Statistics for Factor Returns}

Referring to Table 1, it should be noted that Panel A shows the summary statistics for factors' returns. The findings further show that only HML is statistically significant at the five per cent level of confidence. The average HML return is 0.67 per cent per month $(t=2.29)$, with a standard deviation of 3.04 per cent. The value premium is higher for the small stocks. The average return for the $\mathrm{HML}_{\mathrm{s}}$ is 1.16 per cent per month $(t=5.01)$ with a standard deviation of 2.41 per cent. Therefore, these values suggest the existence of a value premium within the stock market of the MENA region. Although the size, INV, OP, MOM, and ILLIQ effects do not seem to be present in our data samples, the factors' premiums are noted to be higher for the small stocks.

Referring to Table 1 again, Panel B highlights the correlation matrix between all the factors. The negative correlation between the market and the size reflects evidence of a reverse size effect. The highest correlation is observed to be between the value, and the INV factors, with a positive value of 0.59 , which demonstrate that the value stocks comprised of more conservative stocks rather than growth stocks.

The value factor is positively correlated with the ILLIQ factor which imply that the growth stocks are more liquid than the value stocks. The value factor is also positively correlated with size, OP and MOM factors. The MOM is positively correlated with ILLIQ, which indicates that the winner stocks are more illiquid than the loser stocks. OP is negatively correlated with ILLIQ, which shows that the more robust portfolios are more liquid. INV is positively correlated with size, value, MOM, OP and ILLIQ. These results suggest that in the MENA region, the small stocks are the value, conservative, robust, illiquid and loser stocks.

\subsection{Summary Statistics for the Portfolios' Excess Returns}

This section presents the summary statistics for the different size-sort portfolios of the LHS. Panel A of Table 2 shows the average monthly excess returns, and the standard deviations for the 25 size- $\mathrm{B} / \mathrm{M}$ value- 
Table 1: Summary Statistics for Factors' Average Monthly Returns

Panel A: Averages, standard deviations and t-statistics for monthly returns

\begin{tabular}{lccc}
\hline & Mean & Std dev. & t-statistics \\
\hline$R_{\mathrm{M}, \mathrm{t}} \mathrm{R}_{\mathrm{ft}}$ & 0.75 & 4.31 & 1.81 \\
$\mathrm{SMB}$ & 0.24 & 3.67 & 0.67 \\
$\mathrm{HML}$ & 0.67 & 3.04 & 2.29 \\
$\mathrm{RMW}$ & 0.10 & 2.31 & 0.46 \\
$\mathrm{CMA}$ & -0.14 & 2.48 & -0.61 \\
$\mathrm{WML}$ & -1.16 & 6.98 & -1.72 \\
$\mathrm{ILML}$ & 0.80 & 6.29 & 1.31 \\
$\mathrm{HML}$ & 0.18 & 5.44 & 0.34 \\
$\mathrm{HML}_{\mathrm{s}}$ & 1.16 & 2.41 & 5.01 \\
RMW $_{\mathrm{s}}$ & 0.17 & 3.74 & 0.47 \\
RMW $_{\mathrm{b}}$ & 0.04 & 4.30 & 0.09 \\
$\mathrm{CMA}_{\mathrm{s}}$ & 0.35 & 2.09 & 1.73 \\
$\mathrm{CMA}_{\mathrm{b}}$ & -0.64 & 4.18 & -1.58 \\
$\mathrm{WML}_{\mathrm{s}}$ & -0.88 & 5.87 & -1.55 \\
$\mathrm{WML}_{\mathrm{b}}$ & -1.44 & 9.76 & -1.53 \\
$\mathrm{ILML}_{\mathrm{s}}$ & 1.58 & 6.42 & 2.56 \\
$\mathrm{ILML}_{\mathrm{b}}$ & 0.01 & 11.32 & 0.00 \\
\hline
\end{tabular}

Panel B: Correlations between different factors

\begin{tabular}{lccccccr}
\hline & $\mathrm{R}_{\mathrm{M}, \mathrm{t}}-\mathrm{R}_{\mathrm{ft}}$ & $\mathrm{SMB}$ & $\mathrm{HML}$ & $\mathrm{CMA}$ & $\mathrm{RMW}$ & $\mathrm{WML}$ & ILML \\
\hline $\mathrm{R}_{\mathrm{M}, \mathrm{t}}-\mathrm{R}_{\mathrm{ft}}$ & 1.00 & & & & & & \\
$\mathrm{SMB}$ & -0.68 & 1.00 & & & & & \\
$\mathrm{HML}$ & -0.23 & 0.39 & 1.00 & & & & \\
$\mathrm{CMA}$ & -0.56 & 0.52 & 0.59 & 1.00 & & & \\
RMW & 0.21 & 0.01 & 0.37 & 0.13 & 1.00 & & \\
WML & 0.30 & -0.18 & 0.19 & 0.09 & 0.06 & 1.00 & \\
ILML & -0.56 & 0.41 & 0.25 & 0.49 & -0.19 & 0.04 & 1.00 \\
\hline
\end{tabular}

Notes: Panel A shows average monthly returns, expressed in percentage (mean), the standard deviation of the monthly returns (std. dev.) and the corresponding $t$-statistics. Panel B shows the correlations between the different factors. 
Table 2: Summary Statistics for the Different Size-Sort Portfolios Excess Returns

Panel A: Monthly excess return for size-B/M 25 portfolios

\begin{tabular}{lrccccccccc}
\hline & Low & 2 & 3 & 4 & High & Low & 2 & 3 & 4 & High \\
\hline Small & 0.63 & 0.63 & 1.05 & 1.51 & 2.15 & 5.19 & 3.06 & 3.42 & 3.95 & 5.03 \\
2 & -0.49 & 0.06 & 0.80 & 1.22 & 1.37 & 5.71 & 3.87 & 4.76 & 5.71 & 4.44 \\
3 & 0.02 & 0.78 & 0.46 & 1.00 & 1.3 & 4.80 & 3.80 & 4.89 & 5.09 & 5.89 \\
4 & -0.20 & 0.21 & -0.04 & 0.55 & 0.72 & 4.26 & 4.82 & 4.38 & 4.66 & 5.98 \\
Big & 0.78 & 0.79 & 0.73 & -0.1 & 1.04 & 8.16 & 7.74 & 4.49 & 5.38 & 6.35
\end{tabular}

Panel B: Monthly excess return for size-INV portfolios

\begin{tabular}{lcccccccccr}
\hline & Cons. & \multicolumn{1}{c}{2} & \multicolumn{1}{c}{3} & 4 & Agg. & Cons. & 2 & 3 & 4 & Agg. \\
\hline Small & 2.46 & 1.06 & 0.49 & 1.43 & 1.28 & 6.54 & 3.75 & 2.76 & 4.97 & 4.24 \\
2 & 0.32 & 0.92 & 1.50 & 0.65 & 0.49 & 4.42 & 3.80 & 4.50 & 4.55 & 5.26 \\
3 & 0.64 & 1.26 & 0.83 & 0.51 & 0.25 & 5.10 & 5.01 & 4.29 & 4.16 & 5.32 \\
4 & 0.15 & -0.05 & -0.19 & 0.44 & 0.21 & 3.58 & 4.29 & 4.23 & 4.79 & 5.42 \\
Big & 0.15 & 0.94 & 0.60 & 0.44 & 0.91 & 3.64 & 6.43 & 5.51 & 8.00 & 7.96 \\
\hline
\end{tabular}

Panel C: Monthly excess return for size-OP portfolios

\begin{tabular}{lcccccccccc}
\hline & Weak & 2 & 3 & 4 & Robust & Weak & 2 & 3 & 4 & Robust \\
\hline Small & 2.37 & 1.28 & 0.70 & 1.16 & 1.52 & 6.43 & 3.85 & 2.35 & 3.97 & 4.75 \\
2 & 0.29 & 0.81 & 1.26 & 0.88 & 1.07 & 4.91 & 4.22 & 3.69 & 5.09 & 5.82 \\
3 & 0.82 & 0.65 & 0.62 & 0.34 & 1.24 & 5.79 & 4.51 & 4.82 & 4.47 & 5.59 \\
4 & -0.49 & 0.22 & -0.05 & 0.38 & 0.23 & 4.83 & 5.26 & 4.07 & 4.36 & 4.55 \\
Big & 0.34 & 0.56 & 0.48 & 0.58 & 0.43 & 6.11 & 5.65 & 5.14 & 5.08 & 7.67 \\
\hline
\end{tabular}

Panel D: Monthly excess return for size-MOM portfolios

\begin{tabular}{lcccccccccc}
\hline & Looser & 2 & 3 & 4 & Winner Looser & 2 & 3 & 4 & Winner \\
\hline Small & 3.28 & 1.62 & 0.99 & 1.03 & 1.64 & 10.69 & 4.56 & 3.29 & 4.46 & 5.54 \\
2 & 1.43 & 0.49 & 0.89 & 0.08 & 0.11 & 6.56 & 3.75 & 3.08 & 0.35 & 6.07 \\
3 & 1.36 & 0.61 & 0.38 & 0.17 & 0.62 & 7.51 & 3.42 & 3.13 & 3.88 & 7.67 \\
4 & 0.88 & 0.08 & 0.31 & -0.50 & 0.06 & 4.61 & 4.22 & 4.51 & 5.97 & 6.13 \\
Big & 0.98 & 0.06 & -0.12 & 0.07 & -0.74 & 7.01 & 7.36 & 5.66 & 7.82 & 12.48 \\
\hline
\end{tabular}

Panel E: Monthly excess return for size-ILLIQ portfolios

\begin{tabular}{lrccrcc}
\hline & Low & 2 & High & Low & 2 & High \\
\hline Small & 0.25 & 1.74 & 2.15 & 2.81 & 7.97 & 5.89 \\
2 & -0.01 & 1.36 & 1.75 & 8.36 & 9.99 & 5.93 \\
Big & -0.79 & 0.22 & 0.11 & 10.86 & 5.80 & 3.08 \\
\hline
\end{tabular}

Notes: This table reports the mean and standard deviation of the excess returns for the 25 size-B/M, 25 size INV, 25 size-OP, 25 size MOM and 9 size-ILLIQ portfolios. 
weighted portfolios. Looking at the relationship between size and average excess returns (the size effect), we notice that the stocks in the right column of the size- $\mathrm{B} / \mathrm{M}$ matrix exhibit a standard size effect; the small-value stocks tend to have higher excess returns than the largevalue stocks in the last size quintile.

In the left two columns of the size- $\mathrm{B} / \mathrm{M}$ matrix, the small-growth stock portfolios tends to present lower excess returns as compared to the large-growth stock portfolios. In each column of the three right quintiles of $\mathrm{B} / \mathrm{M}$, the average excess return drops from small to large stock portfolios.

Therefore, we can say that this may be evidenced of the size effect. In terms of the relationship between $\mathrm{B} / \mathrm{M}$ and average excess returns (the value effect), each size row in Panel A of Table 2 shows that average excess returns increase from low $\mathrm{B} / \mathrm{M}$ to high $\mathrm{B} / \mathrm{M}$ stock portfolios. The extreme small stocks in the first row of the size quintiles tend to have higher return premiums than the extreme large stocks in the last size quintile. However, in Panel B of Table 2, we observed that average excess returns in all INV quintiles have a standard size effect. This effect is more robust in the left INV quintile, which include the extremely conservative INV stocks. The smallest portfolio in the conservative INV quintile has the highest excess returns of all. Thus, we can say that there is evidence of a size effect on INV portfolios.

Examining the relationship between INV and average excess returns (the INV effect), we observed that average excess returns in the first and the third rows of the size quintile dropped from the portfolios in the left column to the right column. Therefore, the INV effect is noted to be unclear in our samples.

Panel C of Table 2 shows that average excess returns of the size$\mathrm{OP}$ in general had decreased in size. We observed that the size effect is more robust in the left column which include extremely weak OP stocks. Analysing the relationship between OP and average excess returns (the OP effect), each size row in Panel $C$ of Table 2 shows that average excess returns tend to increase in a non-monotonic manner, except for the first size row in which the extremely weak portfolio has a higher return than the extremely robust portfolio. This suggests that there might be an OP effect in our sample, particularly among the large stocks.

Panel D of Table 2 shows the patterns in the average excess returns of size-MOM portfolios. In all columns of MOM quintiles, average excess returns fall from small to large stocks. This result is more robust in the last column which includes the winner stocks, and it is smoother for 
the loser stocks. In relation to the relationship between MOM and the average excess returns (the MOM effect), each size row in Panel D of Table 2 shows that the average excess returns have decreased from the loser to the winner's portfolios, which reveal that there is no standard MOM effect in the MENA region.

Panel E of Table 2 shows average excess returns for size-ILLIQ portfolios. In this panel, the standard size effect is clear. The small stock portfolios tend to be riskier than the large stock portfolios, but they also have higher excess returns. Analysing the relationship between the ILLIQ and average excess returns (the ILLIQ effect), each size row signifies that the average excess returns have increased from low ILLIQ portfolios to high ILLIQ portfolios. This implies that there might be an ILLIQ effect in the MENA region. This effect appears to be more robust for the smallest size quintile.

\section{Findings and Discussion}

In this section, we tested how well each model explained average excess returns on the different portfolios. The objective is to determine which factor has captured average stock returns and which served as the best model for explaining these portfolios returns in the MENA markets. Using a time-series approach, we estimated and analysed the models as expressed in Equations (11) to (18).

\subsection{The GRS Test}

Table 3 shows the results of the GRS test, and the summary statistics for the regression intercepts used for size-B/M portfolios. ${ }^{8}$ Our righthand side (RHS) factors serve as the market factors: SMB, HML, CMA, WMR, WML, and ILML. We calculated these factors as described in section 3.1. By combining and comparing these factors, we are able to assess which of these is the best model. To examine the effectiveness of the asset-pricing model, a high value of the GRS statistic is considered as undesirable; a small P-value implies that we could reject the null hypothesis which states that all the intercepts are jointly equal to zero.

Since our main interest is to compare the models' relative performance, we compared the average absolute value of the regression

\footnotetext{
${ }^{8}$ The GRS of the other size sorts present similar results regarding the superiority of the sevenfactor model. The results are available upon request.
} 
Table 3: GRS Test for Portfolios Formed on Size-B/M

\begin{tabular}{lcccccc}
\hline Model & GRS & $|\mathrm{a}|$ & $\mathrm{R}^{2}$ & $\mathrm{P}(\mathrm{GRS})$ & $\mathrm{S}(\mathrm{a})$ & $\mathrm{SR}(\mathrm{a})$ \\
\hline CAPM & 3.658 & 0.527 & 0.556 & 0.000 & 0.322 & 1.072 \\
Three- & 3.144 & 0.433 & 0.629 & 0.000 & 0.303 & 1.048 \\
Four-MOM & 2.558 & 0.353 & 0.640 & 0.001 & 0.311 & 0.994 \\
Four-ILLIQ & 3.134 & 0.431 & 0.633 & 0.000 & 0.309 & 1.079 \\
Five- & 3.076 & 0.437 & 0.644 & 0.000 & 0.303 & 1.072 \\
Six-MOM & 2.506 & 0.349 & 0.653 & 0.001 & 0.309 & 1.012 \\
Six-ILLIQ & 2.967 & 0.421 & 0.647 & 0.000 & 0.310 & 1.087 \\
Seven- & 2.289 & 0.328 & 0.656 & 0.003 & 0.319 & 1.009 \\
\hline
\end{tabular}

Notes: This table reports summary statistics for regressions of monthly excess returns on portfolios formed on size-B/M. The GRS statistic tests whether all intercepts in the set of $5 \times 5$ regressions are zero; $|\mathrm{a}|$ is the average absolute value of the intercepts; $R^{2}$ is the average, adjusted $R^{2} ; S(a)$ is the average standard error of the intercepts; $\mathrm{SR}(\mathrm{a})$ is the square of the Sharpe ratio for the intercepts; $\mathrm{P}(\mathrm{GRS})$ is the p-value for the GRS statistic.

intercepts $|a|$, regression average adjusted $R^{2}$, intercepts standard deviations $\mathrm{S}(\mathrm{a})$, the P-values, and the models' unexplained squared Sharpe ratios SR(a), across the models. The lower absolute intercepts, lower intercepts' standard deviations, lower squared Sharpe ratios, higher P-values, and higher average adjusted $\mathrm{R}^{2}$ all point to the better performance of the model.

Table 3 also provides evidence which proves that the three-factor model can significantly enhance the model's performance, above the CAPM, as observed by the higher $\mathrm{R}^{2}$, lower GRS, lower S(a), and lower $\operatorname{SR}(\mathrm{a})$.

Table 3 also provide evidence which shows that both the four-factor models improved on the three-factor model's performance, as depicted by the higher $\mathrm{R}^{2}$, lower GRS, lower S(a), and lower SR(a). The five-factor model enhanced the performance of both the four-factor models as noted by the higher $\mathrm{R}^{2}$, lower GRS, lower S(a) and lower SR(a). Both the sixfactor models performed better than the five-factor model, and the sevenfactor model performed better than all the other competing models.

Based on the outcomes generated and shown in Table 3, it is noted that the best model among these eight models is the seven-factor model, which carries the highest $\mathrm{R}^{2}(0.656)$, the lowest GRS (2.289), the lowest $|\mathrm{a}|(0.328)$, the highest P-value (0.003), and the second lowest SR(a), with a value of 1.009 . 
Based on this, it can be deduced that when using the GRS test, not all the models under analysis can fully explain the portfolios' excess returns. The seven-factor model, the six-factor-ILLIQ model, and the four-factor-ILLIQ model, appear to be the three best-performing models.

\subsection{Models Performance Robustness Tests}

As an additional analysis, we used the AIC and the differences in the mean adjusted $\mathrm{R}^{2}$ to compare the performance of the different models again. Table 4 reports on the AIC for all the models for all the LHS portfolio sets. The lowest AIC value is noted to be in the seven-factor model for all the LHS sets.

Table 4: AIC for the Alternative Models for Portfolios Formed on Different Size-Sort

\begin{tabular}{lccccc}
\hline Model & Size-B/M & Size-INV & Size-OP & Size-MOM & Size-ILLIQ \\
\hline CAPM & 555 & 545 & 550 & 665 & 717 \\
Three- & 538 & 531 & 535 & 591 & 623 \\
Four-MOM & 534 & 529 & 533 & 560 & 621 \\
Four-ILLIQ & 537 & 531 & 535 & 591 & 614 \\
Five- & 535 & 526 & 529 & 590 & 623 \\
Six-MOM & 532 & 524 & 527 & 560 & 621 \\
Six-ILLIQ & 535 & 526 & 529 & 591 & 613 \\
Seven- & 532 & 524 & 527 & 561 & 611 \\
\hline
\end{tabular}

Notes: The Table reports the AIC for the different models. The AIC is the average of all portfolios' AIC for each model for each size sort set.

Table 5 reports on the mean adjusted $R^{2}$ that resulted from the bootstrapping method used for each asset pricing model which considered the portfolios based on the size-B/M sort. From the results shown in Table 5, it can be concluded that the three-factor model's adjusted $R^{2}$ is significantly different from the CAPM's adjusted $R^{2}$ since the P-value of the difference was zero. Thus, we reject the null hypothesis which states that the difference between the two models' adjusted $R^{2}$ is zero. The five-factor model's adjusted $R^{2}$ is also significantly different from the three-factor model's adjusted $\mathrm{R}^{2}$ and from the four-factor-ILLIQ model's adjusted $R^{2}$. Nonetheless, it is not significantly different from the Carhart four-factor model's adjusted $R^{2}$. 
Table 5: Differences in the Mean Adjusted $\mathrm{R}^{2}$ of the Alternative Asset Pricing Models for the Size-B/M Portfolios

\begin{tabular}{|c|c|c|c|c|c|c|c|c|}
\hline Variable & CAPM & Three- & $\begin{array}{l}\text { Four- } \\
\text { MOM }\end{array}$ & $\begin{array}{l}\text { Four- } \\
\text { ILLIQ }\end{array}$ & Five- & $\begin{array}{l}\text { Six- } \\
\text { MOM }\end{array}$ & $\begin{array}{c}\text { Six- } \\
\text { ILLIQ }\end{array}$ & Seven- \\
\hline Mean $\mathrm{R}^{2}$ & 0.56 & 0.64 & 0.65 & 0.65 & 0.66 & 0.67 & 0.67 & 0.68 \\
\hline CAPM & - & $\begin{array}{c}0.08 \\
(0.00)\end{array}$ & $\begin{array}{c}0.09 \\
(0.00)\end{array}$ & $\begin{array}{c}0.09 \\
(0.00)\end{array}$ & $\begin{array}{c}0.10 \\
(0.00)\end{array}$ & $\begin{array}{c}0.11 \\
(0.00)\end{array}$ & $\begin{array}{c}0.11 \\
(0.00)\end{array}$ & $\begin{array}{c}0.12 \\
(0.00)\end{array}$ \\
\hline Three- & & - & $\begin{array}{c}0.01 \\
(0.00)\end{array}$ & $\begin{array}{c}0.01 \\
(0.00)\end{array}$ & $\begin{array}{c}0.02 \\
(0.00)\end{array}$ & $\begin{array}{c}0.03 \\
(0.00)\end{array}$ & $\begin{array}{c}0.03 \\
(0.00)\end{array}$ & $\begin{array}{c}0.04 \\
(0.00)\end{array}$ \\
\hline Factor-MOM & & & - & $\begin{array}{l}-0.01 \\
(0.14)\end{array}$ & $\begin{array}{c}0.01 \\
(0.25)\end{array}$ & $\begin{array}{c}0.02 \\
(0.00)\end{array}$ & $\begin{array}{c}0.01 \\
(0.03)\end{array}$ & $\begin{array}{c}0.03 \\
(0.00)\end{array}$ \\
\hline Four-ILLIQ & & & & - & $\begin{array}{c}0.01 \\
(0.00)\end{array}$ & $\begin{array}{c}0.03 \\
(0.00)\end{array}$ & $\begin{array}{c}0.02 \\
(0.00)\end{array}$ & $\begin{array}{c}0.03 \\
(0.00)\end{array}$ \\
\hline Five- & & & & & - & $\begin{array}{c}0.01 \\
(0.00)\end{array}$ & $\begin{array}{c}0.01 \\
(0.00)\end{array}$ & $\begin{array}{c}0.02 \\
(0.00)\end{array}$ \\
\hline Six-MOM & & & & & & - & $\begin{array}{l}-0.01 \\
(0.11)\end{array}$ & $\begin{array}{c}0.01 \\
(0.00)\end{array}$ \\
\hline Six-ILLIQ & & & & & & & - & $\begin{array}{c}0.01 \\
(0.00)\end{array}$ \\
\hline
\end{tabular}

Notes: This table reports the mean adjusted $\mathrm{R}^{2}$ for each model considering the portfolios resulting from the size-B/M sort and the difference between the adjusted $\mathrm{R}^{2}$ for each two models and the corresponding p-value (reported in parentheses) on the test if the difference is equal to zero, obtained using the bootstrap method.

The seven-factor model's adjusted $\mathrm{R}^{2}$ is significantly different from all the other models' adjusted $\mathrm{R}^{2}$.

Therefore, it can be said that Table 5 confirms the GRS and the AIC results which highlighted all the eight model's performance difference, which are quite significant. Hence, this also validates the superiority of the seven-factor model.

\subsection{Regression Details Analysis}

To obtain a deeper understanding of the performance of each model, we further examine and discuss the regression estimates, specifically, the intercepts and factors' slopes, and their associated t-statistics. Table 6 summarises the intercepts and the factors' slopes for the seven-factor 
Table 6: Seven-Factor Model Regressions Estimates for the 25 Size-B/M Portfolios

\begin{tabular}{|c|c|c|c|c|c|c|c|c|c|c|}
\hline & Low & 2 & 3 & 4 & High & Low & 2 & 3 & 4 & High \\
\hline & \multicolumn{5}{|c|}{$a$} & \multicolumn{5}{|c|}{$t(a)$} \\
\hline Small & -0.17 & -0.09 & 0.24 & 0.84 & 0.94 & -0.34 & -0.41 & 0.91 & 2.57 & 2.46 \\
\hline 1 & -1.35 & -0.53 & 0.01 & 0.06 & 0.12 & -3.11 & -1.75 & 0.02 & 0.21 & 0.51 \\
\hline 2 & -0.22 & 0.39 & -0.33 & -0.03 & -0.06 & -0.60 & 1.61 & -1.46 & -0.10 & -0.22 \\
\hline 3 & -0.46 & 0.02 & -0.34 & -0.18 & 0.10 & -2.02 & 0.09 & -1.65 & -0.81 & 0.30 \\
\hline \multirow[t]{2}{*}{ Big } & 0.12 & 0.25 & 0.47 & -0.21 & 1.03 & 0.36 & 0.63 & 2.01 & -0.64 & 2.33 \\
\hline & \multicolumn{5}{|c|}{$b$} & \multicolumn{5}{|c|}{$t(b)$} \\
\hline Small & 0.90 & 0.62 & 0.69 & 0.58 & 1.05 & 4.65 & 5.66 & 5.76 & 5.84 & 7.71 \\
\hline 1 & 1.03 & 0.71 & 0.94 & 1.26 & 0.95 & 5.75 & 7.66 & 7.53 & 11.50 & 11.67 \\
\hline 2 & 0.56 & 0.52 & 0.93 & 0.94 & 1.26 & 5.37 & 5.59 & 11.99 & 7.97 & 10.98 \\
\hline 3 & 0.69 & 0.61 & 0.69 & 0.75 & 0.88 & 6.83 & 7.54 & 9.24 & 9.32 & 5.64 \\
\hline \multirow[t]{2}{*}{ Big } & 1.36 & 1.02 & 0.56 & 0.61 & 0.23 & 10.38 & 4.10 & 6.13 & 6.19 & 1.61 \\
\hline & \multicolumn{5}{|c|}{$s$} & \multicolumn{5}{|c|}{$t(s)$} \\
\hline Small & 0.54 & 0.33 & 0.25 & 0.34 & 0.49 & 2.98 & 2.85 & 1.73 & 2.91 & 4.03 \\
\hline 1 & 0.41 & 0.16 & 0.39 & 0.26 & 0.30 & 2.28 & 1.34 & 3.40 & 2.14 & 2.79 \\
\hline 2 & 0.08 & -0.02 & 0.13 & 0.24 & 0.05 & 0.77 & -0.14 & 1.65 & 2.30 & 0.32 \\
\hline 3 & 0.03 & -0.25 & -0.20 & -0.19 & -0.47 & 0.42 & -2.35 & -2.37 & -2.26 & -2.40 \\
\hline \multirow[t]{2}{*}{ Big } & -0.73 & -0.80 & -0.54 & -0.67 & -1.53 & -7.07 & -3.98 & -8.42 & -6.77 & -10.61 \\
\hline & \multicolumn{5}{|c|}{$h$} & \multicolumn{5}{|c|}{$t(h)$} \\
\hline Small & -0.29 & 0.04 & 0.13 & 0.10 & 0.12 & -1.66 & 0.35 & 1.45 & 0.84 & 1.01 \\
\hline 1 & -0.24 & 0.00 & -0.04 & 0.05 & 0.37 & -1.74 & -0.04 & -0.29 & 0.36 & 3.87 \\
\hline 2 & -0.32 & 0.00 & 0.00 & 0.12 & 0.52 & -2.87 & -0.04 & -0.02 & 1.27 & 3.33 \\
\hline 3 & -0.30 & -0.16 & -0.11 & 0.33 & 0.60 & -4.11 & -2.16 & -1.36 & 4.68 & 3.66 \\
\hline \multirow[t]{2}{*}{ Big } & -0.45 & -0.20 & 0.05 & 0.31 & 0.95 & -4.21 & -1.05 & 0.67 & 3.20 & 5.40 \\
\hline & \multicolumn{5}{|c|}{$c$} & \multicolumn{5}{|c|}{$t(c)$} \\
\hline Small & 0.36 & -0.05 & 0.18 & -0.36 & 0.13 & 1.57 & -0.36 & 1.01 & -2.43 & 0.69 \\
\hline 1 & -0.06 & -0.07 & -0.04 & -0.13 & -0.19 & -0.29 & -0.39 & -0.28 & -0.68 & -1.56 \\
\hline 2 & -0.12 & -0.24 & -0.39 & -0.32 & 0.04 & -0.73 & -1.71 & -2.07 & -1.56 & 0.23 \\
\hline 3 & 0.15 & 0.09 & -0.01 & -0.59 & 0.00 & 1.40 & 0.62 & -0.08 & -4.19 & 0.02 \\
\hline Big & 0.05 & -0.49 & -0.28 & 0.01 & 0.17 & 0.30 & -2.19 & -2.52 & 0.08 & 0.97 \\
\hline
\end{tabular}


Table 6: Continued

\begin{tabular}{|c|c|c|c|c|c|c|c|c|c|c|}
\hline & Low & 2 & 3 & 4 & High & Low & 2 & 3 & 4 & High \\
\hline & \multicolumn{5}{|c|}{$r$} & \multicolumn{5}{|c|}{$t(r)$} \\
\hline Small & 0.23 & -0.01 & -0.01 & 0.12 & 0.09 & 1.06 & -0.05 & -0.07 & 0.98 & 0.75 \\
\hline 1 & 0.13 & -0.37 & -0.11 & -0.19 & 0.17 & 0.63 & -2.91 & -0.94 & -1.85 & 1.91 \\
\hline 2 & 0.32 & 0.10 & -0.05 & -0.02 & 0.20 & 2.70 & 0.95 & -0.46 & -0.20 & 1.75 \\
\hline 3 & 0.26 & 0.34 & 0.24 & 0.09 & 0.05 & 2.73 & 3.34 & 3.07 & 0.94 & 0.39 \\
\hline \multirow[t]{2}{*}{ Big } & -0.22 & 0.30 & 0.29 & 0.22 & 0.60 & -1.70 & 1.49 & 3.48 & 2.39 & 3.69 \\
\hline & \multicolumn{5}{|c|}{$m$} & \multicolumn{5}{|c|}{$t(m)$} \\
\hline Small & -0.07 & -0.03 & -0.10 & 0.11 & -0.02 & -1.07 & -0.88 & -3.27 & 2.03 & -0.34 \\
\hline 1 & 0.09 & -0.05 & 0.03 & -0.05 & -0.11 & 1.85 & -1.39 & 0.68 & -0.95 & -2.78 \\
\hline 2 & 0.01 & -0.02 & 0.01 & -0.19 & -0.03 & 0.32 & -0.51 & 0.22 & -3.86 & -0.57 \\
\hline 3 & 0.08 & 0.00 & 0.08 & 0.03 & 0.04 & 3.13 & 0.14 & 3.42 & 0.99 & 0.66 \\
\hline \multirow[t]{2}{*}{ Big } & -0.32 & 0.06 & -0.03 & 0.18 & -0.02 & -5.76 & 0.48 & -0.73 & 4.64 & -0.45 \\
\hline & \multicolumn{5}{|c|}{ il } & \multicolumn{5}{|c|}{$t(i l)$} \\
\hline Small & -0.01 & 0.04 & 0.01 & 0.08 & 0.10 & -0.08 & 0.58 & 0.21 & 0.91 & 1.01 \\
\hline 1 & 0.07 & 0.00 & -0.03 & 0.02 & 0.02 & 0.66 & -0.04 & -0.36 & 0.26 & 0.28 \\
\hline 2 & -0.13 & -0.08 & -0.02 & -0.12 & 0.07 & -1.59 & -1.34 & -0.26 & -2.15 & 0.90 \\
\hline 3 & -0.05 & -0.13 & -0.02 & 0.02 & -0.10 & -0.97 & -2.49 & -0.34 & 0.49 & -1.07 \\
\hline Big & -0.08 & 0.21 & 0.02 & -0.01 & -0.03 & -1.01 & 1.35 & 0.32 & -0.20 & -0.36 \\
\hline
\end{tabular}

Notes: This table reports regressions estimates and their t-statistics for the seven-factor model. The LHS variables are the monthly excess returns on the 25 size-B/M portfolios. The RHS are market excess returns, $R_{M, t}-R_{f t}$ size factor (SMB), value factor (HML), MOM factor (WML), ILLIQ factor (ILML), OP factor (RMW), and INV factor (CMA).

model by considering the size-B/M portfolios. ${ }^{9}$ The results for this model show that several of the analysed portfolios have intercepts which are insignificantly different from zero. Insignificant intercepts show that the model can explain the stock returns. This result is further confirmed by the GRS test, AIC analysis, and the adjusted $\mathrm{R}^{2}$ difference analysis presented above. The portfolios' slopes differ from one factor to another. The market slopes are high for most of the portfolios while some are higher than one. The significant market slopes indicate that the market

\footnotetext{
${ }^{9}$ The regression details of other portfolio sets and other models are available upon request.
} 
risk factor is a relevant risk factor in the MENA region. The SMB slopes are statistically positive for all the small stocks; this means that there is a standard size effect among those small stock portfolios.

As can be noted, the slopes are statistically negative for all the large stocks in all the models. This could be a sign of the reverse size effect of these large stocks. The SMB slope for the large-value portfolio (-1.53, $t=-10.61)^{10}$ is the lowest value among all the SMB slopes. The HML slopes for the value portfolios are statistically positive, and higher than the slopes of the growth portfolios, which are negative, and some are significant.

The HML slope for the large-value portfolio $(0.95, t=5.40)$ is the highest slope in the HML slopes which mean that the value factor is a priced risk factor. The slopes of the CMA are negative in general; six slopes are statistically significant and negative. The INV slope for the large-value portfolio $(0.17, t=0.97)$ is the second-highest slope, hence it can be concluded that there is no clear INV effect in our sample. The RMW slopes are positive in general; nine slopes are statistically significant and positive, whereas three slopes are statistically significant and negative. The OP slope for the large-value portfolio $(0.60, t=3.69)$ is the highest slope. This evidence shows the OP effect in our sample. Moreover, the slopes of the WML factor, in general, are insignificant for most of the portfolios. The MOM slope for the large-value portfolio $(-0.02, t=-0.45)$ is the second-highest slope among the value portfolios. Thus, the MOM effect seems unclear.

The ILLIQ slopes carry just two significant values. This means that there may be no ILLIQ effect in our sample. This may be caused by the fact that the portfolios which we use to construct the ILML factor are not well-diversified, given the small number of stocks that are frequently traded. In relation to the large-value portfolio, the factors' slopes suggest that this portfolio is dominated by large stocks where the returns have behaved like those of profitable, aggressive, illiquid firms that had grown slowly.

Relating this finding to the other models, we observed that the number of portfolios exhibiting significant intercepts had generally decreased as we added more factors. The multifactor models' slopes show similar results as those of the seven-factor model mentioned above.

\footnotetext{
${ }^{10} \mathrm{t}$-statistics are calculated from standard errors that are robust to heteroskedasticity, using the method of White (1980).
} 
The market, SMB, HML, and RMW factors contain in the models using them are found to be relevant for the MENA region. Although our results do not show clear evidence of the ILLIQ effect, when we analysed the portfolios formed from the size-ILLIQ sorts, we found a positive and significant ILML slope for the extremely small-illiquid portfolio.

\subsection{Discussion}

From the outcomes generated, and explained above, it can be concluded that this study has generated sufficient evidence to show the standard size effect of the small size portfolios, and the reverse size effect of large size portfolios for the MENA region, based on the regression details derived for the size- $\mathrm{B} / \mathrm{M}$ sort portfolios (and other size sort sets). There is evidence of the value effect too since most of the HML slopes are significantly positive for the value stocks in all the models. This further indicates that the value portfolios have higher returns than the growth portfolios. There is also ample evidence highlighting the profitability effect since most of the slopes had been positive and significant. However, there is no clear evidence supporting the effect of momentum, illiquidity, and investment within the MENA region.

Our results on the size, and value factors, seem consistent with Van der Hart et al. (2003), who had found both size and value to be relevant risk factors for all the emerging markets they studied. Our results related to illiquidity are consistent with Rouwenhorst (1999) who had found the illiquidity factor not to be a priced factor for the emerging markets being studied. Nevertheless, the portfolios which we have used to construct this factor are found to be not well-diversified, and this could be attributed to the small number of stocks that are being frequently traded. In relation to investment, our finding is consistent with other studies, such as Fama and French (2017), who had found that this factor is not present in the European and Asia Pacific markets. Looking at momentum, our result is in harmony with Cakici et al. (2013), who had noted that no momentum effect persist in the Eastern Europe emerging market. The absence of the momentum effect may be attributed to the argument proposed by Chui, Titman, and Wei (2010) who noted that the momentum returns were more robust in countries that valued individualism. Most of the countries in our datasets are characterised by the low value individualism index. This is further evidenced by Rouibah, Khalil and Hassanien (2009) who showed that the average individualism index score for the MENA markets was 40.5, which had 
been construed as a collectivist culture. Overall, our findings seem to be consistent with the conclusions of Zhang (2017) who observed that "investment and momentum effects were stronger in developed markets than in emerging markets".

Thus in summary, we conclude that although the results of our study have indicated that the seven-factor model was the most promising model to be used for explaining the stock returns in the MENA markets, no particular factor seems to dominate on a regular basis. In the current study, the short sample period, and the fastchanging market conditions caused by the political and economic instability of the MENA region during the period of study may have caused the priced risk factors to be different during the different subperiods. Moreover, it could also be attributed to the different factors being measured in different ways.

\section{Conclusion}

Empirical evidence noted in previous studies had shown that besides market factors, numerous factors contribute to the pattern of asset returns. Focusing on the less explored region of the Middle East and North Africa, this paper has examined the return patterns of the emerging and less developed stock markets of the 13 countries involved. This study has also examined whether the factors found to be significant in explaining the stock returns in developed and other emerging markets are also significant for the MENA markets. In this regard, we find a significant standard size effect in the small size portfolios. We also find the reverse size effect of the large size portfolios in our current research samples. We also uncover a significant value effect, with some evidence of a profitability effect. However, we find no clear evidence of the investment, momentum and illiquidity effect, although the illiquid portfolios present higher returns than the liquid ones, particularly for the small sized portfolios. This finding is thus not consistent with the expectation that illiquidity is a priced factor in emerging markets. We attribute this limitation to the measures we engaged for evaluating this factor.

Looking at the alternative asset pricing models, our results show that market factors alone cannot explain the excess returns on the MENA stocks. Thus, the inclusion of size and value help to improve the explanatory power of the CAPM, but it was still significantly rejected. The inclusion of the profitability and the investment factor further improve the performance of the three-factor model, but the model is still 
significantly rejected. The inclusion of the momentum and the illiquidity factor enhanced the model's explanatory power, and the models that do so become more acceptable when we use the GRS test. The best model based on the intercepts analysis, the GRS test, the AIC analysis and the adjusted $\mathrm{R}^{2}$ differences analysis are the seven-factor model, in all size sorts.

The findings generated by the current study carry important implications for portfolio management, and portfolio performance evaluation, in emerging markets, specifically the MENA region. The findings also carry essential and practical implications for many interested participants in this region, such as national investors, international investors, and policy makers. Our findings provide evidence highlighting the importance of other additional factors which ought to be considered by investors in the emerging financial markets who wish to diversify their risks or to achieve higher excess returns. For the purpose of portfolio performance evaluation in the MENA markets our results show that the seven-factor model is the most promising model to be applied.

The current study is also constrained by a few limitations. First, the study period has been relatively short. Second, from the 21 countries that composed the MENA region, we are only able to obtain data for 13 countries. This is attributed to the fact that not all the 21 countries are included in the DataStream database. Those not in the database include Yemen, and some countries do not have any available information, for example, Syria. Third, the analysis of the different markets with different levels of development may affect the reliability of the data that we obtained since each has a different variation in terms of culture and practices. Fourth, the study period is derived from a crisis period, which could also affect our results. Some of these limitations may, nevertheless, be addressed by future research. It would be of interest to analyse further whether the models' performance have changed in different subperiods, and whether different factor measurements carry any effect on the performance of the respective models.

\section{References}

Aharoni, G., Grundy, B., \& Zeng, Q. (2013). Stock returns and the Miller Modigliani valuation formula: Revisiting the Fama French analysis. Journal of Financial Economics, 110(2), 347-357. http://dx.doi.org/10.1016/j. jfineco.2013.08.003 
Amihud, Y. (2002). Illiquidity and stock returns: Cross-section and time-series effects. Journal of Financial Markets, 5(1), 31-56. http://dx.doi.org/10.1016/ s13864181(01)00024-6

Amihud, Y., \& Mendelson, H. (1986). Asset pricing and the bid-ask spread. Journal of Financial Economics, 17(2), 223-249. http://dx.doi.org/10.1016/ 0304-405x(86)90065-6

Banz, R.W. (1981). The relationship between return and market value of common stocks. Journal of Financial Economics, 9(1), 3-18. http://dx.doi. org/10.1016/0304-405x(81)90018-0

Barillas, F., \& Shanken, J. (2018). Comparing asset pricing models. The Journal of Finance, 73(2), 715-754. http://dx.doi.org/10.1111/jofi.12607

Barry, C.B., Goldreyer, E., Lockwood, L., \& Rodriguez, M. (2002). Robustness of size and value effects in emerging equity markets, 1985-2000. Emerging Markets Review, 3(1), 1-30. http:/ / dx.doi.org/10.1016/s1566-0141(01)00028-0

Basu, S. (1983). The relationship between earnings' yield, market value and return for NYSE common stocks: Further evidence. Journal of Financial Economics, 12(1), 129-156. http:/ /dx.doi.org/10.1016/0304-405X(83)90031-4

Blackburn, D.W., \& Cakici, N. (2017). Frontier stock markets: Local vs global factors (Gabelli School of Business, Fordham University Research Paper No. 2930491). New York, NY: Fordham University. Retrieved from SSRN: https:// ssrn.com/abstract=2930491

Brailsford, T., Gaunt, C., \& O'Brien, M.A. (2012). Size and book-to-market factors in Australia. Australian Journal of Management, 37(2), 261-281. http://dx.doi. org $/ 10.1177 / 0312896211423555$

Brennan, M.J., \& Subrahmanyam, A. (1996). Market microstructure and asset pricing: On the compensation for illiquidity in stock returns. Journal of Financial Economics, 41(3), 441-464. http://dx.doi.org/10.1016/0304405x(95)00870-k

Cakici, N., Fabozzi, F.J., \& Tan, S. (2013). Size, value, and momentum in emerging market stock returns. Emerging Markets Review, 16(September), 46-65. http://dx.doi.org/10.1016/j.ememar.2013.03.001

Carhart, M.M. (1997). On persistence in mutual fund performance. The Journal of Finance, 52(1), 57-82. http:/ / dx.doi.org/10.2307/2329556

Chui, A.C., Titman, S., \& Wei, K.J. (2010). Individualism and momentum around the world. The Journal of Finance, 65(1), 361-392. http://dx.doi.org/10.1111/ j.1540-6261.2009.01532.x

Dey, M.K. (2005). Turnover and return in global stock markets. Emerging Markets Review, 6(1), 45-67. http://dx.doi.org/10.1016/j.ememar.2004.09.003

Fama, E.F., \& French, K.R. (1992). The cross-section of expected stock returns. The Journal of Finance, 47(2), 427-465. http://dx.doi.org/10.2307/2329112

Fama, E.F., \& French, K.R. (1993). Common risk factors in the returns on stocks and bonds. Journal of Financial Economics, 33(1), 3-56. http://dx.doi.org/ $10.1016 / 0304-405 x(93) 90023-5$ 
Fama, E.F., \& French, K.R. (2015). A five-factor asset pricing model. Journal of Financial Economics, 116(1), 1-22. http://dx.doi.org/10.1016/j.jfineco.2014. 10.010

Fama, E.F., \& French, K.R. (2016). Dissecting anomalies with a five-factor model. The Review of Financial Studies, 29(1), 69-103. http://dx.doi.org/10.1093/ rfs/hhv043

Fama, E.F., \& French, K.R. (2017). International tests of a five-factor asset pricing model. Journal of Financial Economics, 123(3), 441-463. http://dx.doi.org/ 10.1016/j.jfineco.2016.11.004

Fama, E.F., \& French, K.R. (2018). Choosing factors. Journal of Financial Economics, 128(2), 234-252. http://dx.doi.org/10.1016/j.jineco.2018.02.012

Gibbons, M.R., Ross, S.A., \& Shanken, J. (1989). A test of the efficiency of a given portfolio. Econometrica: Journal of the Econometric Society, 7(5), 1121-1152. http://dx.doi.org/10.2307/1913625

Griffin, J.M. (2002). Are the Fama and French factors global or country specific? The Review of Financial Studies, 15(3), 783-803. http://dx.doi.org/10.1093/ rfs/15.3.783

Hanauer, M.X., \& Linhart, M. (2015). Size, Value, and Momentum in Emerging Market Stock Returns: Integrated or Segmented Pricing? Asia-Pacific Journal of Financial Studies, 44(2), 175-214. http:/ /dx.doi.org/10.1111/ajfs.12086

Hearn, B. (2009). Liquidity and valuation in East African securities markets. South African Journal of Economics, 77(4), 553-576. http://dx.doi.org/ 10.1111/j.1813-6982.2009.01229.x

Hearn, B., \& Piesse, J. (2010). Modelling size and illiquidity in West African equity markets. Applied Financial Economics, 20(13), 1011-1030. http:// dx.doi.org/10.1080/09603101003724364

Hou, K., Xue, C. \& Zhang, L., (2015). Digesting anomalies: An investment approach. The Review of Financial Studies, 28(3), 650-705. http:/ /dx.doi.org/ $10.1093 /$ rfs/hhu068

Hou, K., Mo, H., Xue, C., \& Zhang, L. (2019). Which factors? Review of Finance, 23(1), 1-35. http://dx.doi.org/10.1093/rof/rfy032

Hu, G.X., Chen, C., Shao, Y., \& Wang, J. (2019). Fama-French in China: Size and value factors in Chinese stock returns. International Review of Finance, 19(1), 3-44. http:/ / dx.doi.org/10.1111/irfi.12177

Jegadeesh, N., \& Titman, S. (1993). Returns to buying winners and selling losers: Implications for stock market efficiency. The Journal of Finance, 48(1), 65-91. http://dx.doi.org/10.1111/j.1540-6261.1993.tb04702.x

Lagoarde-Segot, T., \& Lucey, B.M. (2008). The capital markets of the Middle East and North African region: Situation and characteristics. Emerging Markets Finance and Trade, 44(5), 68-81. http://dx.doi.org/10.2753/ree1540$496 \times 440505$

Lintner, J. (1965). The valuation of risk assets and the selection of risky investments in stock portfolios and capital budgets. The Review of Economics and Statistics, 47(1), 13-37. http://dx.doi.org/10.2307/1924119 
Liu, J., Stambaugh, R.F., \& Yuan, Y. (2018). Size and value in China (NBER Working Paper, No. w24458). Cambridge, MA: National Bureau of Economic Research. http://dx.doi.org/10.3386/w24458

Lo, A.W., \& MacKinlay, A.C. (1990). When are contrarian profits due to stock market overreaction? The Review of Financial Studies, 3(2), 175-205. http:// dx.doi.org/10.1093/rfs/3.2.175

Merton, R.C. (1973). An intertemporal capital asset pricing model. Econometrica: Journal of the Econometric Society, 41(5), 867-887. http://dx.doi.org/10.2307/ 1913811

Mossin, J. (1966). Equilibrium in a capital asset market. Econometrica: Journal of the Econometric Society, 34(4), 768-783. https://dx.doi.org/10.2307/1910098

Mwaura, M.F., \& Nyaboga, A.B. (2011). International financial accounting standards and the continent of Africa. International Business $\mathcal{E}$ Economics Research Journal, 8(3), 33-46. http://dx.doi.org/10.19030/iber.v8i3.3113

Novy-Marx, R. (2013). The other side of value: The gross profitability premium. Journal of Financial Economics, 108(1), 1-28. http://dx.doi.org/10.1016/j. jfineco.2013.01.003

Rosenberg, B., \& Marathe, V. (1976). Common factors in security returns: Microeconomic determinants and macroeconomic correlates (Research Program in Finance, Working Papers, No. 44). Berkeley, CA: University of California at Berkeley.

Ross, S.A. (1976). The arbitrage theory of capital asset pricing. Journal of Economic Theory, 13(3), 341-360. http:/ / dx.doi.org/10.1016/0022-0531(76)90046-6

Rouibah, K., Khalil, O.E., \& Hassanien, A.E. (2009). Emerging markets and e-commerce in developing economies. Hershey, New York: IGI Global.

Rouwenhorst, K.G. (1999). Local return factors and turnover in emerging stock markets. The Journal of Finance, 54(4), 1439-1464. http://dx.doi.org/ 10.1111/0022-1082.00151

Sharpe, W.F. (1964). Capital asset prices: A theory of market equilibrium under conditions of risk. The Journal of Finance, 19(3), 425-442. http://dx.doi. org/10.1111/j.1540-6261.1964.tb02865.x

Treynor, J.L. (1962). Jack Treynor's "Toward a theory of market value of risky assets". Retrieved from http://dx.doi.org/10.2139/ssrn.628187

Van der Hart, J., Slagter, E., \& Van Dijk, D. (2003). Stock selection strategies in emerging markets. Journal of Empirical Finance, 10(1-2), 105-132. http://dx. doi.org/10.1016/s0927-5398(02)00022-1

White, H. (1980). A heteroskedasticity-consistent covariance matrix estimator and a direct test for heteroskedasticity. Econometrica: Journal of the Econometric Society, 48(4), 817-838. http://dx.doi.org/10.2307/1912934

Zhang, L. (2017). The investment CAPM. European Financial Management, 23(4), 545-603. http://dx.doi.org/10.1111/eufm.12129 